\title{
Exploring morphological effects on the mechanics of blended PLA/PCL extruded fibers fabricated using multilayer coextrusion
}

\author{
Kris M. Van de Voorde, ${ }^{a}$ Jonathan K. Pokorski, ${ }^{\text {bc }}$ and LaShanda T. J. Korley ${ }^{\text {a,d }}$ \\ ${ }^{a}$ Department of Materials Science and Engineering, University of Delaware Newark, Delaware, 19716, United States \\ ${ }^{b}$ Department of Nanoengineering, University of California San Diego, La Jolla, California, 92093, United States \\ ${ }^{\mathrm{c}}$ Institute for Materials Discovery and Design, University of California San Diego, La Jolla, California, 92093, United States \\ ${ }^{d}$ Department of Chemical Engineering, University of Delaware, Newark, Delaware, 19716, United States
}

Ph: (302) 831-0937 E-mail: lkorley@udel.edu

Ph: (858) 246-3183 E-mail: jpokorski@ucsd.edu

SUPPLEMENTAL INFORMATION 


\section{Fiber purity obtained via ${ }^{1} \mathrm{H}$ nuclear magnetic resonance (NMR) spectroscopy PEO \\ PLA \\ PCL<smiles>CO[CH]CC1CC1</smiles><smiles>CC(C)=C(C)C(C)C</smiles><smiles>CC(C)=O</smiles>

The integral area of peak $a$ in the ${ }^{1} \mathrm{H}$ NMR is set to 1.00 to determine the ratio of the area included in peak $e$ and $g$ to peak $a$. Peak $e$ represents two protons in each PCL repeat unit. Peak $g$

$$
\begin{aligned}
& \frac{\frac{a \text { mol PEO }}{4}}{\frac{\text { e mol PCL }}{2}}=\frac{a}{2 e} \frac{\mathrm{mol} \mathrm{PEO}}{\mathrm{mol} P C L} \\
& \frac{\frac{a \text { mol PEO }}{4}}{\frac{g \text { mol PLA }}{1}}=\frac{a}{4 g} \frac{\mathrm{mol} \mathrm{PEO}}{\mathrm{mol} \mathrm{PLA}}
\end{aligned}
$$

Equation S1

Equation S2

represents a single proton in each PLA repeat unit and peak $a$ represents four protons in each PEO repeat unit. This integral ratio can be utilized to determine the relative mole fraction of each repeat unit present.

After determining the molar ratio of the PEO to PCL and PEO to PLLA, we convert the molar ratio to weight ratios using the molar masses of the single repeat units $(\mathrm{PEO}=44.05 \mathrm{~g} / \mathrm{mol}$, PCL $=114.14 \mathrm{~g} / \mathrm{mol}$, and PLA $=72.06 \mathrm{~g} / \mathrm{mol}$ ).

$$
\begin{aligned}
& \left(\frac{a}{4 g}\right)\left(\frac{m o l ~ P E O}{m o l P L A}\right)\left(\frac{1 \text { mol } P L A}{72.03 g P L A}\right)\left(\frac{44.05 g \text { PEO }}{1 \text { mol PEO })}\right)=0.153 \frac{a}{g} \frac{g P E O}{g P L A} \quad \text { Equation S3 } \\
& \left(\frac{a}{2 e}\right)\left(\frac{m o l ~ P E O}{m o l ~ P C L}\right)\left(\frac{1 \text { mol } P C L}{114.14 g P C L}\right)\left(\frac{44.05 g \text { PEO }}{1 \text { mol } P E O)}\right)=0.193 \frac{a g P E O}{e} \quad \text { Equation S4 }
\end{aligned}
$$

To determine integrations, the area for peak $a$ is set to 1.00 , simplifying these relationships to only include one variable each $(e$ and $g$ ).

$$
\begin{aligned}
& 0.193 \frac{a}{e} \frac{g P E O}{g P C L}=0.193 \frac{1}{e} \frac{g P E O}{g P C L}=\frac{0.193}{e} \frac{g P E O}{g P C L} \\
& 0.153 \frac{a}{g} \frac{g P E O}{g P L A}=0.153 \frac{1}{g} \frac{g P E O}{g P L A}=\frac{0.153}{g} \frac{g P E O}{g P L A}
\end{aligned}
$$

Equation S6

We assume a $1 \mathrm{~g}$ PCL and $1 \mathrm{~g}$ PLA basis, and then determine the corresponding weight of PEO that would result from the peak integration ratios given.

$$
\begin{aligned}
& \left(\frac{0.193}{e} \frac{g P E O}{g P C L}\right)(1 g \text { PCL })=\frac{0.193}{e} g \text { PEO } \\
& \left(\frac{0.153}{g} \frac{g \text { PEO }}{g \text { PLA }}\right)(1 \mathrm{~g} \text { PLA })=\frac{0.153}{g} g \text { PEO }
\end{aligned}
$$


The weight percentage ( $\mathrm{wt} \%$ ) of PCL and PLA in the composite is then calculated by using the 1 $\mathrm{g}$ and $1 \mathrm{~g}$ PLA value. This $1 \mathrm{~g}$ PCL and $1 \mathrm{~g}$ PLA basis is determined through the integration ratios calculated from ${ }^{1} \mathrm{H}$ NMR.

$$
\begin{aligned}
& \text { wt \% of PCL }=\frac{1 g P C L}{1 g P C L+\frac{0.193}{e} g P E O} * 100 \%=\frac{1 g P C L}{\left(1+\frac{0.193}{e}\right) g \text { total }} * 100 \% \\
& =\frac{1}{1+\frac{0.193}{e}} * 100=\frac{1}{\frac{e+0.193}{e}} * 100 \\
& w t \% \text { of PLA }=\frac{1 g \text { PLLA }}{1 g \text { PLLA }+\frac{0.153}{g} \text { gPEO }} * 100 \%=\frac{1 g \text { PLLA }}{\left(1+\frac{0.153}{g}\right) \text { g total }} * 100 \% \\
& =\frac{1}{1+\frac{0.153}{g}} * 100=\frac{1}{\frac{g+0.153}{g}} * 100
\end{aligned}
$$

Equation S10

To determine the $\mathrm{wt} \%$ of the total polyester content of the fibers, the wt $\%$ of both the PCL and PLA components are added together along with a factor, $x$, that accounts for the original wt $\%$ of the components that were blended together originally $(1,0.75,0.5,0.25$, and 0$)$

$$
w t \% \text { of Polyester }=\left(x \frac{1}{\frac{e+0.193}{e}}+(1-x) \frac{1}{\frac{g+0.153}{g}}\right) * 100
$$

\section{Isolated Non-woven Fibers}

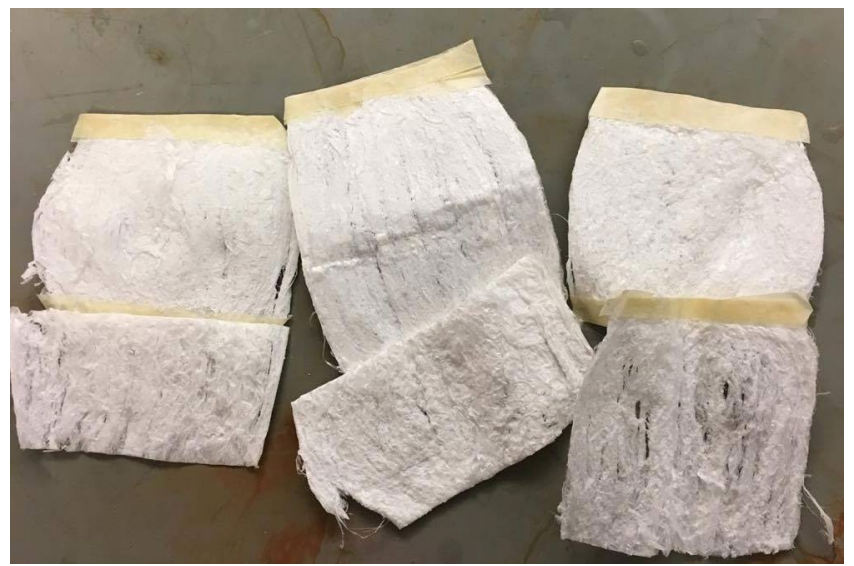

Figure S1. Photographs of isolated, non-woven fibers 


\section{Fiber Dimensions}

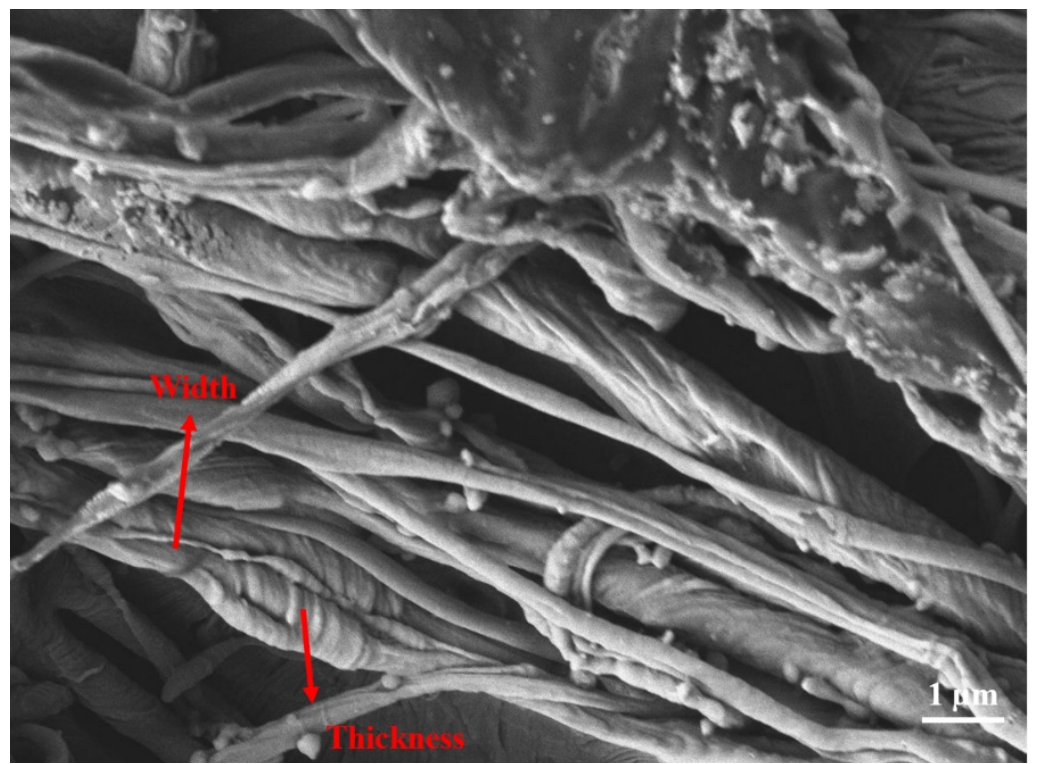

Figure S2. SEM micrograph of PCL fibers indicating the location of the width and thickness of the rectangular fibers

\section{Void fraction calculations}

Table S1. The length, width, and thicknesses were measured for each sample set. The specimen was then weighed. Using the density of the polymer pellets used during coextrusion, the void space was calculated.

\begin{tabular}{|l|r|r|r|r|}
\hline & 25 PCL & 50 PCL & 75 PCL & 100 PCL \\
\hline $\mathrm{L}(\mathrm{mm})$ & 7.7 & 5.9 & 6.0 & 4.5 \\
\hline $\mathrm{W}(\mathrm{mm})$ & 5.5 & 5.8 & 6.7 & 5.3 \\
\hline $\mathrm{T}(\mathrm{mm})$ & 0.63 & 0.62 & 0.58 & 0.44 \\
\hline $\mathrm{M}(\mathrm{g})$ & 10 & 9.1 & 11 & 5.9 \\
\hline $\mathrm{V}(\mathrm{mL})$ & 27 & 21. & 23 & 11 \\
\hline Density $(\mathrm{g} / \mathrm{mL})$ & 0.39 & 0.423 & 0.46 & 0.56 \\
\hline density(pellets) $(\mathrm{g} / \mathrm{mL})$ & 1.2 & 1.2 & 1.2 & 1.1 \\
\hline void space & 0.69 & 0.64 & 0.61 & 0.51 \\
\hline
\end{tabular}

The fiber void fraction was determined by measuring the apparent density of the fibers, which was achieved by cutting the samples into rectangles and calculating the volume.

$$
\mathrm{V}=(\mathrm{L})(\mathrm{W})(\mathrm{T})
$$

Equation S12 
The length (L), width (W), and thickness (T) were measured. The samples were then weighed on an analytical balance to obtain their mass (M). These two values were then used to find the density.

$$
\rho=\frac{M}{V}
$$

Equations S13

The apparent density $(\varphi)$ of each system was then found, where $\rho_{P C L}=1.15 \mathrm{~g} / \mathrm{mL}$ and $\rho_{P L A}=$ $1.25 \mathrm{~g} / \mathrm{mL}$.

$$
\varphi_{\text {fiber }}=\frac{\left[\left(w_{P C L}\right)\left(\rho_{P C L}\right)+\left(w_{P L A}\right)\left(\rho_{P L A}\right)\right]-\rho}{\left[\left(w_{P C L}\right)\left(\rho_{P C L}\right)+\left(w_{P L A}\right)\left(\rho_{P L A}\right)\right]} \quad \text { Equation S14 }
$$

Cross-sectional areas of the fibers were measured using a micrometer and corrected for porosity. A Zwick/Roell mechanical testing instrument equipped with a $100 \mathrm{~N}$ load cell was utilized to perform uniaxial tensile test at $50 \% \mathrm{~min}^{-1}$ at room temperature. Each specimen was tested a minimum of five times per sample. 


\section{Thermal behavior obtained from differential scanning calorimetry (DSC)}

Table S2. Enthalpic values and melting/cold crystallization/crystallization temperatures obtained from the first heating cycle of DSC tests utilized to calculate crystallinity.

\begin{tabular}{|c|c|c|c|c|c|c|c|c|}
\hline System & $\begin{array}{c}\Delta \mathbf{H}_{\mathrm{cc}}(\mathbf{P L A}) \\
(\mathrm{J} / \mathrm{g})\end{array}$ & $\begin{array}{c}\Delta \mathbf{H}_{\mathrm{m}}(\mathbf{P L A}) \\
(\mathrm{J} / \mathrm{g})\end{array}$ & $\begin{array}{c}\Delta \mathbf{H}_{\mathrm{m}}(\mathbf{P C L}) \\
(\mathrm{J} / \mathrm{g})\end{array}$ & $\begin{array}{c}\mathbf{T}_{\mathbf{m}, \mathbf{P L A}} \\
\left({ }^{\circ} \mathbf{C}\right)\end{array}$ & $\begin{array}{c}\mathbf{T}_{\text {cc,PLA }} \\
\left({ }^{\circ} \mathbf{C}\right)\end{array}$ & $\begin{array}{c}\mathbf{T}_{\mathbf{c}, \mathrm{PLA}} \\
\left({ }^{\circ} \mathbf{C}\right) \\
\end{array}$ & $\begin{array}{c}\mathbf{T}_{\mathrm{m}, \mathrm{PCL}} \\
\left({ }^{\circ} \mathrm{C}\right)\end{array}$ & $\begin{array}{l}\mathbf{T}_{\mathrm{c}, \mathrm{PCL}} \\
\left({ }^{\circ} \mathbf{C}\right)\end{array}$ \\
\hline \multirow[t]{3}{*}{100 PLA/0 PCL } & 3.2 & 32.1 & - & 150 & 82 & 89 & - & - \\
\hline & 3.4 & 34.2 & - & 152 & 82 & 99 & - & - \\
\hline & 3.2 & 35.4 & - & 150 & 82 & 100 & - & - \\
\hline \multirow[t]{3}{*}{75 PLA/25 PCL } & 1.0 & 23.0 & 11.91 & 151 & 79 & 92 & 61 & 34 \\
\hline & 1.0 & 23.1 & 13.3 & 150 & 80 & 93 & 60 & 34 \\
\hline & 0.94 & 23.0 & 13.117 & 149 & 83 & 93 & 60 & 34 \\
\hline \multirow[t]{3}{*}{50 PLA/50 PCL } & 0 & 17.1 & 17.1 & 150,110 & - & 115,85 & 61 & 34 \\
\hline & 0 & 19.6 & 19.6 & 151,110 & - & 114,84 & 61 & 33 \\
\hline & 0 & 19.6 & 19.6 & 152,110 & - & 101,85 & 61 & 34 \\
\hline \multirow[t]{3}{*}{25 PLA/75 PCL } & 0 & 7.65 & 39.4 & 110 & - & 100 & 61 & 34 \\
\hline & 0 & 7.61 & 34.8 & 110 & - & 100 & 61 & 35 \\
\hline & 0 & 9.22 & 33.9 & 109 & - & 100 & 61 & 35 \\
\hline \multirow[t]{3}{*}{0 PLA/100 PCL } & - & - & 51.8 & - & - & - & 61 & 32 \\
\hline & - & - & 58.2 & - & - & - & 61 & 32 \\
\hline & - & - & 53.2 & - & - & - & 62 & 32 \\
\hline
\end{tabular}

Interesting thermo behavior was observed in the PLA domain when added with greater amounts of PCL. Because of fractionated crystallization, heterogenous crystallites were formed within the PLA domain and two melting temperatures as well as two crystallization temperatures were observed.

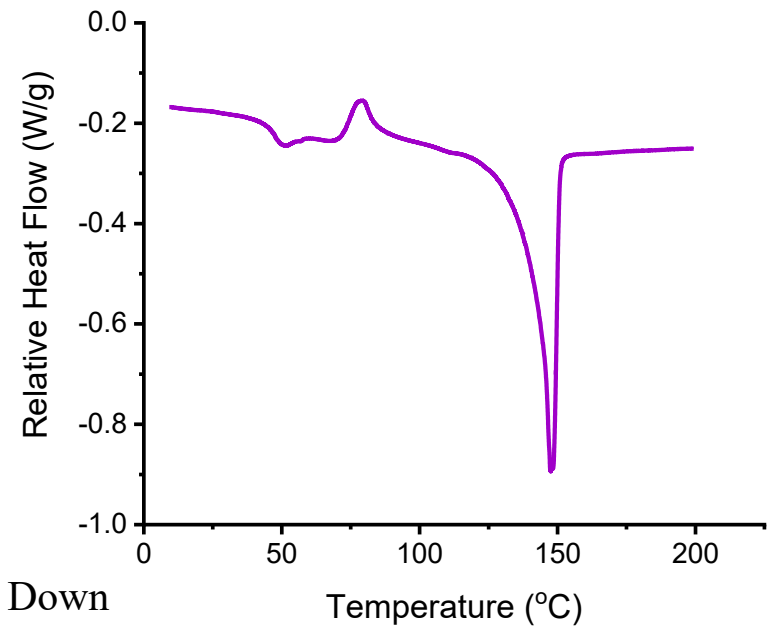

Figure S3. $1^{\text {st }}$ Heating cycle of PLA fibers, where the glass transition temperature was measured at 50 ${ }^{\circ} \mathrm{C}$, cold crystallization is measured at $82{ }^{\circ} \mathrm{C}$, and the melting temperature is measured at $147{ }^{\circ} \mathrm{C}$. 